\title{
A NEW ApPROACH TO OPTIMAL COMMODITY TAXATION
}

\author{
STEFAN HOMBURG
}

CESIFO WORKING PAPER NO. 1231

CATEGORY 1: Public FinANCE

JULY 2004

- from the CESifo website: www.CESifo.de 


\title{
A New APPROACH TO OPTIMAL COMMODITY TAXATION
}

\begin{abstract}
This paper makes a fresh attempt at characterizing optimal commodity taxes. Under the usual assumptions, an extremely simple expression of second-best commodity taxes is derived, showing tax rates as functions of observable variables only, rather than as functions of unobservable variables such as compensated cross elasticities. The main formula is independent of special preferences, and independent of the number of commodities. It has a simple economic meaning and could be particularly useful for empirical research. Examples and remarks on the normalization problem are provided.
\end{abstract}

JEL Classification: H21.

Keywords: optimal commodity taxation, Ramsey rule.

Stefan Homburg

School of Economics and Management

University of Hannover

Königsworther Platz 1

30167 Hannover

Germany

homburg@fiwi.uni-hannover.de 


\section{INTRODUCTION}

For more than one and a half centuries, economists have been trying to characterize commodity taxes which minimize the excess burden of taxation. Ramsey (1927) surmounted the partial equilibrium framework of Dupuit (1844) and others, laying the foundation for the modern treatment. Research on this topic is still continuing, and if one takes to hand a contemporary textbook ${ }^{1}$ or a recent survey ${ }^{2}$ in order to pick up the fruits of these efforts, it turns out that the theory of public finance essentially offers three answers to the question as to how a policy maker should set commodity taxes optimally. However, each of the three answers has so severe shortcomings that they are almost useless for practical purposes. In the order of decreasing popularity ${ }^{3}$, the answers have become known as the Ramsey rule, the inverse elasticity rule, and the Corlett-Hague rule. Let us review these briefly.

- The Ramsey rule characterizes optimal changes in consumption, stating that optimal taxes diminish all demands in the same proportion. In fact, this interpretation holds only approximately in the neighbourhood of zero tax revenue.

- According to the inverse elasticity rule, optimal commodity tax rates are inversely proportional to elasticities of demand. This presupposes a very special form of the utility function and is far from a general result.

- Finally, the Corlett-Hague rule yields a substantive conclusion for any wellbehaved preferences. It states that in a setting with two consumption goods and leisure, precisely that good which is more complementary with leisure should be taxed at a higher rate. But unfortunately, we live in a world with considerably more than two commodities.

This paper makes a fresh attempt at characterizing optimal commodity taxes. Concentrating on efficiency issues and thus adopting a framework with identical consumers $^{4}$, a very simple rule for optimal commodity taxes will be derived. This rule holds independently of special assumptions on preferences, and independently of the number of commodities. It entails an explicit formula for optimal tax rates in terms of observable variables. Regarding empirical applications, an explicit solution in terms of observable variables seems important and useful; after all, the fact that most traditional results are formulated in terms of compensated

1 E. g. Myles (1995).

2 E. g. Auerbach and Hines (2002).

3 To get an approximate measure of popularity, I performed an internet search which, at the time it was conducted, entailed over 1.000 hits for "Ramsey rule", roughly 500 hits for "inverse elasticity rule" and less than 100 hits for "Corlett-Hague rule".

4 For a recent treatment of distributional aspects of commodity taxation, see Coady and Drèze (2002). 
elasticities is often considered as an eminent obstacle for putting the theory into practice.

The paper is organized as follows. Section 2 presents the standard approach in a nutshell, in order to facilitate comparison with the new approach. Section 3 contains our principal result. A general complementarity rule is derived in section 4 . Some examples are provided in section 5 . Section 6 considers optimal commodity taxes in the presence of an additional wage tax, and section 7 concludes. The appendix clarifies some minor points of rigour.

The common underlying framework is this one, where all symbols in bold face represent n-vectors: Consumers maximize utilities $u(x, y)$ by selecting a pair of consumption $x$ and effort $y$ from a given consumption set $C$, subject to the budget constraint $\mathrm{y} \geq \boldsymbol{q} \boldsymbol{x}$ and at given consumer prices $\boldsymbol{q}$. Gross and net wage rates being normalized to unity, $y$ represents earnings in monetary units as well as effort in hours. Forming a Lagrangean $\mathcal{L}=u(\boldsymbol{x}, y)+\mu(y-\boldsymbol{q} \boldsymbol{x})$ and differentiating it with respect to the choice variables gives

$$
\frac{\partial u}{\partial \boldsymbol{x}}=\mu \boldsymbol{q} \text { and } \frac{\partial u}{\partial y}=-\mu
$$

\section{Characterizing Optimal QuANTITIES}

The prevailing dual approach does not aim to describe optimal taxes, but seeks to characterize optimal quantities. It employs ordinary demand functions $\boldsymbol{x}(\boldsymbol{q})$ which, under suitable assumptions on preferences, are defined for any $\boldsymbol{q}>>\mathbf{0}$. The addingup restriction defines an earnings function $y(\boldsymbol{q})=\boldsymbol{q} \boldsymbol{x}(\boldsymbol{q})$ and entails the Cournot aggregation $\partial y / \partial \boldsymbol{q}=\boldsymbol{x}+\boldsymbol{q} \partial \boldsymbol{x} / \partial \boldsymbol{q}$. Using consumer prices as controls, the government maximizes utilities subject to the revenue constraint $\boldsymbol{t} x \geq g$, where $g$ is an exogenous revenue requirement, $\boldsymbol{t}=\boldsymbol{q}-\boldsymbol{p}$ are the commodity taxes, and $\boldsymbol{p}$ represents given producer prices ${ }^{5}$. Differentiating $\mathcal{L}=u(\boldsymbol{x}(\boldsymbol{q}), y(\boldsymbol{q}))+\lambda(\boldsymbol{t} \boldsymbol{x}(\boldsymbol{q})-g)$ with respect to the controls yields

$$
\frac{\partial u}{\partial \boldsymbol{x}} \frac{\partial \boldsymbol{x}}{\partial \boldsymbol{q}}+\frac{\partial u}{\partial y} \frac{\partial y}{\partial \boldsymbol{q}}+\lambda\left(\boldsymbol{x}+\boldsymbol{t} \frac{\partial \boldsymbol{x}}{\partial \boldsymbol{q}}\right)=\mathbf{0}
$$

since $\partial t / \partial \boldsymbol{q}=\mathbf{I}$. This leads to the uncompensated version of the Ramsey rule, if we substitute from (1) and the Cournot aggregation:

$$
\boldsymbol{t} \frac{\partial \boldsymbol{x}}{\partial \boldsymbol{q}}=-\frac{\lambda-\mu}{\lambda} \boldsymbol{x}
$$

Ramsey (1927) assumed utility to be quasi-linear in effort. Then, as there are no income effects, the expression on the left involves a symmetric matrix and may be

5 It is well-known that all results remain unchanged in case of endogenous producer prices. 
re-written as $\partial \boldsymbol{x} / \partial \boldsymbol{q} \boldsymbol{t}$. According to the mean-value theorem, this equals the changes in demands, $\boldsymbol{d} \boldsymbol{x}$, when taxes are increased from zero to $\boldsymbol{d t}$. Hence, all demands are diminished by a common factor.

In the presence of income effects, one can use the Slutsky decomposition to obtain the compensated version of the Ramsey rule, originally developed by Samuelson (1951). For some negative constant $k$ and the Slutzky matrix $\boldsymbol{S}$, this reads:

$$
\boldsymbol{S t}=k \boldsymbol{x} .
$$

Optimal taxes diminish the compensated demands by a common factor. Using Mirrlees' (1976) term "index of discouragement" for $\Sigma_{j} S_{i j} t_{j} / x_{i}$, the Ramsey rule asserts that the index of discouragement should be the same for all goods.

\section{Characterizing OPTIMAL TAXES}

The primal approach seeks to characterize optimal taxes rather than optimal quantities. It uses inverse demand functions $\boldsymbol{q}(\boldsymbol{x})$ defined for all $\boldsymbol{x} \in D$, where $D$ denotes the image of the demand function $\boldsymbol{x}(\boldsymbol{q})$. Now, the adding-up restriction defines an offer curve $y(\boldsymbol{x})=\boldsymbol{q}(\boldsymbol{x}) \boldsymbol{x}$ and entails the inverse Cournot aggregation $\partial y / \partial \boldsymbol{x}=\boldsymbol{x} \partial \boldsymbol{q} / \partial \boldsymbol{x}+\boldsymbol{q}$. To understand what this means, observe that the government, by selecting appropriate prices, can induce consumers to choose any consumption plan $\boldsymbol{x} \in D$. In so doing, however, the government must ensure that consumers remain on their offer curves. In this sense, earnings are a function of consumption, and the derivative $\partial y / \partial x_{i}$ indicates the response of earnings to a small change in $x_{i}$. The taxes follow from the identity $\boldsymbol{t}(\boldsymbol{x})=\boldsymbol{q}(\boldsymbol{x})-\boldsymbol{p}$ which implies $\partial \boldsymbol{t} / \partial \boldsymbol{x}=\partial \boldsymbol{q} / \partial \boldsymbol{x}$. Taking the quantities as controls, the government maximizes utilities subject to the revenue constraint. Differentiating the Lagrangean $\mathcal{L}=u(\boldsymbol{x}, y(\boldsymbol{x}))+\lambda(\boldsymbol{t}(\boldsymbol{x}) \boldsymbol{x}-g)$ with respect to the controls, we obtain:

$$
\frac{\partial u}{\partial \boldsymbol{x}}+\frac{\partial u}{\partial y} \frac{\partial y}{\partial \boldsymbol{x}}+\lambda\left(\boldsymbol{x} \frac{\partial \boldsymbol{q}}{\partial \boldsymbol{x}}+\boldsymbol{t}\right)=\mathbf{0}
$$

By using (1) and the inverse Cournot aggregation, this becomes

$$
\mu \boldsymbol{q}-\mu \boldsymbol{x} \frac{\partial \boldsymbol{q}}{\partial \boldsymbol{x}}-\mu \boldsymbol{q}+\lambda\left(\boldsymbol{x} \frac{\partial \boldsymbol{q}}{\partial \boldsymbol{x}}+\boldsymbol{t}\right)=\mathbf{0} .
$$

Solving for $\boldsymbol{t}$, we obtain what could be called the inverse Ramsey rule:

$$
\boldsymbol{t}=-\frac{\lambda-\mu}{\lambda} \boldsymbol{x} \frac{\partial \boldsymbol{q}}{\partial \boldsymbol{x}}
$$

Comparison with (3) highlights the duality of the two approaches in a particularly nice fashion. Apart from this aesthetic virtue, the inverse Ramsey rule is as useless as the Ramsey rule itself. However, performing a simple operation that has no 
analogue in the dual approach, one can substitute $\partial y / \partial \boldsymbol{x}-\boldsymbol{q}$ for $\boldsymbol{x} \partial \boldsymbol{q} / \partial \boldsymbol{x}$, using again the inverse Cournot aggregation. This yields our main result:

$$
\boldsymbol{t}=\frac{\lambda-\mu}{\lambda}\left(\boldsymbol{q}-\frac{\partial y}{\partial \boldsymbol{x}}\right)
$$

After a trivial re-calculation, an alternative version of the result reads:

$$
\boldsymbol{t}=\frac{\lambda-\mu}{\mu}\left(\boldsymbol{p}-\frac{\partial y}{\partial \boldsymbol{x}}\right)
$$

The first version is more useful when it comes to applications, as will be shown below. From a theoretical point of view, the second version is more satisfactory because producer prices are exogenous. To get to grips with it, consider a marginal increase in some consumption $x_{i}$. This move costs $p_{i}$ in a first-best context, but $p_{i}-\partial y / \partial x_{i}$ in a second-best context, because this difference represents the derivative of $\boldsymbol{t}(\boldsymbol{x}) \boldsymbol{x}$ with respect to $x_{i}$. As the tax $t_{i}$ itself can be interpreted as the marginal revenue from slightly increasing $x_{i}$, formula (9) equates marginal revenues and marginal costs multiplied by a uniform constant. The crucial elements in determining optimal taxes are the derivatives $\partial y / \partial x_{i}$ which indicate the responses of earnings to changes in the respective consumptions. Owing to the minus sign, the rule asserts that commodities which stimulate earnings should be taxed at low rates, and vice versa.

Before concluding this section, some historical remarks are in order. The first economist adopting the primal approach to optimal commodity taxation was, of course, Ramsey himself, who worked in the Marshallian tradition of what we today call inverse demand. Indeed, Ramsey's central equation (3) is an archaic form of (7). Assuming $\partial \boldsymbol{q} / \partial \boldsymbol{x}$ to be symmetric and taxes to be infinitesimal, he used it to derive his principal result "that optimal taxes diminish the production of all commodities in the same proportion" (Ramsey 1927, p. 54). Atkinson and Stiglitz (1972) also used a primal approach, treating earnings as an additional control and putting the condition (1) that consumers remain on their offer curves as an additional restriction into the Lagrangean. This facilitates describing optimal taxes in terms of the bordered Hessian of the utility function. Deaton (1979) essentially decomposed (7) into compensated prices changes and inverse income effects, using the distance function and the Antonelli matrix, which is a generalized inverse of the Slutsky matrix. Comparing these approaches in an elegant survey, Stern (1986) pointed out that the analyst has the choice between three different matrices: Slutsky, Hessian or Antonelli. The strategy followed above was not to add yet a fourth matrix type, but to let matrices completely disappear from the scene. This entails the simple vector equations (8) and (9) which are easy to interpret in economic terms, as we shall see. 


\section{A Perfectly General Complementarity Rule}

Equation (8) describes optimal taxes in terms of three observable variables, namely, consumer prices, earnings and consumption. To elucidate its economic meaning, let us define the index of encouragement for each commodity:

$$
e_{i}=\frac{\partial y}{\partial x_{i}} \frac{1}{q_{i}} .
$$

The index of encouragement indicates the response of earnings to an increase in the respective expenditure. It may be positive, negative or zero. Dividing some row in (8) by the consumer price, inserting (10), and dividing two such rows yields:

$$
\frac{t_{i} / q_{i}}{t_{j} / q_{j}}=\frac{1-e_{i}}{1-e_{j}}
$$

This states that commodities with a high index of encouragement should be taxed at low rates, and vice versa. To illustrate this proposition, consider brandy and coffee. Brandy is likely to reduce earnings, at least if consumed in larger quantities. If this is true, brandy has a negative index of encouragement, and (11) suggests taxing it at a relatively high rate. By the same token, as long as coffee has a positive impact on earnings, the coffee tax should be low.

The economic logic behind these findings is as follows. Consumers have positive endowments of leisure which, by assumption, cannot be taxed directly. Commodities with a high index of encouragement induce consumers to supply large portions of their endowments in the market. A government restricted to taxing only market demands will stimulate the consumption of such goods since this broadens the tax base. Note, the impossibility of taxing leisure endowments is the driving force behind second-best taxes ${ }^{6}$. Without this restriction, the government could establish a first-best tax system consisting of a tax on the endowments only. The literature sometimes confounds untaxed endowments with untaxed market demands. Clearly, any market demand can be taken as untaxed, because only relative prices matter. For a clarification of this point, see Stern (1986, p. 298) and section 6 below.

Formula (11) is a general complementarity rule, reminiscent of the Corlett-Hague rule:

$$
\frac{t_{i} / q_{i}}{t_{i} / q_{j}}=\frac{\eta_{y i}^{c}-\eta_{i i}^{c}-\eta_{j j}^{c}}{\eta_{y j}^{c}-\eta_{i i}^{c}-\eta_{j j}^{c}}
$$

6 The implicit assumption that leisure is the only good with an untaxable endowment is not restrictive. If there were several such goods, these could be combined into a single Hicksian composite, since the government cannot change their relative prices by hypothesis. 
The symbols on the right-hand side represent the compensated cross elasticities. Corlett and Hague (1953) named commodity $i$ stronger complementary with leisure if $\eta_{\mathrm{yi}}^{\mathrm{c}}>\eta_{\mathrm{yj}}^{\mathrm{c}}$, i.e. if an increase in the $i$-th price induces a stronger compensated increase in earnings, or decrease in leisure, as compared with an increase in the $j$ th price. Equating (11) and (12) shows that commodity $i$ is stronger complementary with leisure if and only if its index of encouragement is lower. In this sense, our approach generalizes the Corlett-Hague rule, which holds only in the presence of just two commodities, whereas (11) holds for arbitrarily many commodities. Moreover, the new rule involves observable variables instead of compensated cross elasticities that are hard to estimate, and is much easier to derive.

However, the most important advantage of the generalized complementarity rule lies in the economic intuition it provides. Let us consider three concrete commodities: cinema visits, watches and newspapers, in order to see what the traditional approach has to tell us regarding their optimal tax treatment. According to Sandmo (1987, p. 89), who worked out the deepest interpretations of the traditional approach, the "set of taxes should be chosen so as to make the role of substitution effects as small as possible". This is in perfect accordance with prevailing intuition, but what does it mean, either mathematically or with respect to the three aforementioned commodities? In mathematical terms, the statement is empty because optimal taxes by no means minimize some norm of the Slutsky matrix. Practically, the statement is empty, too, except in the accustomed special cases of two goods or vanishing cross elasticities.

Using the present approach, one could argue as follows: Cinema visits or other time consuming hobbies are likely to reduce earnings. Therefore, they should be taxed at relatively high rates. On the other hand, it appears difficult to say something useful about the relationship between watches and earnings. According to the principle of sufficient reason, these should be taxed at the normal rate. Finally, reading newspapers has presumably a positive impact on earnings in a knowledge society, which suggests taxing them at a reduced rate. The latter recommendation holds also with respect to all kinds of work related expenditures. These are often deductible under the earnings tax, a feature equivalent to zero tax rates in a pure excise tax system. The preceding examples were chosen with an eye to actual tax provisions which, of course, are quite diverse among countries. Anyway, it appears perfectly sensible to tax commodities with a high index of encouragement at low rates, because these stimulate labour supply and are hence less costly in a second-best context. 


\section{EXAMPLES}

In this section, we would like to provide some examples by considering concrete functional forms. All examples presume a leisure endowment equal to unity, so that $1-\mathrm{y}$ denotes leisure.

1. Cobb-Douglas Utility: Firstly consider the economist's workhorse

$$
u(\boldsymbol{x}, y)=(1-y)^{\alpha_{0}} x_{1}^{\alpha_{1}} \cdot \ldots \cdot x_{n}^{\alpha_{n}},
$$

where the numbers $\alpha_{i}$ sum up to unity. The textbook solutions read $y=1-\alpha_{0}$ and $x_{i}=\alpha_{i} / q_{i}$ for all $\mathrm{i}$. Changes in any consumption do not affect earnings since all expenditure shares, including the share of leisure itself, remain constant. The derivatives $\partial y / \partial x_{i}$ vanish for all goods, hence $e_{i}=0$, and (8) implies taxation at the uniform rate $(\lambda-\mu) / \lambda$.

2. Inverse Elasticity Utility: Next we derive the inverse elasticity rule:

$$
u(\boldsymbol{x}, y)=1-y+u_{1}\left(x_{1}\right)+\ldots+u_{n}\left(x_{n}\right) .
$$

Quasi-linearity in $y$ excludes income effects, so that $\mu=1$. Differentiating the left equation in (1) yields $\partial q_{i} / \partial x_{j}=0$ for all $\mathrm{j} \neq \mathrm{i}$, implying $\partial y / \partial x_{i}=\partial q_{i} / \partial x_{i} x_{i}+q_{i}$. Therefore, the index of encouragement equals

$$
e_{i}=\frac{\partial q_{i}}{\partial x_{i}} \frac{x_{i}}{q_{i}}+1
$$

from which the inverse elasticity rule $t_{i} / q_{i}=-(\lambda-\mu) / \lambda \cdot \partial q_{i} / \partial \mathrm{x}_{\mathrm{i}} \cdot x_{i} / q_{i}$ follows, written itself in a somewhat inverse fashion. Standard textbook wisdom declares that commodities whose demands react stronger to price changes should be taxed at lower rates because quantity reactions induce excess burdens. Though this is literally true under the very stringent assumption on preferences made here, such a view seems misleading. A much more convincing explanation, which already comes close to the intuition behind (11), was offered by Sandmo (1986, p. 92): If the compensated cross elasticities $\eta_{i j}$ vanish for all $i \neq j$, the adding-up property implies $\eta_{y i}=\eta_{i i}$. Therefore, taxing a commodity with a high own elasticity of demand entails a strong reduction in earnings, and hence in tax revenue. From this perspective, the inverse elasticity rule only paraphrases the above contention that goods whose consumption stimulates earnings should be taxed at low rates. In fact, the impact on earnings is again the driving force behind the result, and the utility function (14) presents but a theoretical curiosity, implying a one-to-one correspondence between individual consumption expenditures on the one hand and earnings on the other.

3. Weakly Separable Utility: The following assumption covers a broader class of utility functions. 


$$
u(\boldsymbol{x}, y)=u(v(\boldsymbol{x}), y),
$$

where $v(\boldsymbol{x})$ is a linear-homogenous subutility function. The first order conditions (1) become:

$$
\frac{\partial u(v(\boldsymbol{x}), y)}{\partial v} \frac{\partial v}{\partial \boldsymbol{x}}-\mu \boldsymbol{q}=\boldsymbol{0} \text { and } \frac{\partial u(v(\boldsymbol{x}), y)}{\partial y}=-\mu
$$

Substituting the second equation into the first and multiplying by $\boldsymbol{x}$ yields:

$$
\frac{\partial u(v(\boldsymbol{x}), y)}{\partial v} v(\boldsymbol{x})+\frac{\partial u(v(\boldsymbol{x}), y)}{\partial y} y=0
$$

where Euler's equation $v(\boldsymbol{x})=\partial v / \partial \boldsymbol{x} \boldsymbol{x}$ and the identity $y=\boldsymbol{q} \boldsymbol{x}$ have been exploited. The desired result now follows from differentiating this equation implicitly (demonstrating how neat some proofs become under the primal approach):

$$
\frac{\partial y}{\partial x_{i}}=-\frac{\frac{\partial^{2} u}{\partial v^{2}} \frac{\partial v}{\partial x_{i}} v+\frac{\partial u}{\partial v} \frac{\partial v}{\partial x_{i}}+\frac{\partial^{2} u}{\partial y \partial v} \frac{\partial v}{\partial x_{i}} y}{\frac{\partial^{2} u}{\partial v \partial y} v+\frac{\partial^{2} u}{\partial v^{2}} y+\frac{\partial u}{\partial y}}=\gamma \frac{\partial v}{\partial x_{i}} .
$$

The common factor $\gamma$ is defined by the right-hand equation. As equation (17) asserts that $\partial v / \partial x_{i}=-\partial u / \partial y /(\partial u / \partial v) q_{i}$, the index of encouragement now amounts to $e_{i}=-\partial u / \partial y /(\partial u / \partial v) \gamma$. The index does not vanish in general, but is identical across commodities, implying uniform taxation. In the present case, the marginal rates of substitution of the consumption goods are independent of earnings, and vice versa. Therefore, distorting consumption along an indifference hyper-surface makes the consumption bundle more expensive and leaves earnings unchanged, which cannot be optimal.

4. Stone-Geary Utility: The last example regards utility functions of the form

$$
u(\boldsymbol{x}, y)=(1-y)^{\alpha_{0}}\left(x_{1}-\beta_{1}\right)^{\alpha_{1}} \cdot \ldots \cdot\left(x_{n}-\beta_{n}\right)^{\alpha_{n}},
$$

the numbers $\alpha_{i}$ again summing up to unity. Using $\hat{x}_{i}=x_{i}-\beta_{i}$, we are back in the Cobb-Douglas case and obtain $\hat{x}_{i}=\alpha_{i} / q_{i}$ or $q_{i}=\alpha_{i} /\left(x_{i}-\beta_{i}\right)$, the familiar linear expenditure system. As cross elasticities vanish, $\partial y / \partial x_{i}=-\alpha_{i} x_{i} /\left(x_{i}-\beta_{i}\right)^{2}+\alpha_{i} /\left(x_{i}-\beta_{i}\right)$. Dividing the last expression by the consumer price yields the index of encouragement:

$$
e_{i}=-\frac{\beta_{i} q_{i}}{\alpha_{i}}
$$

As tax rates are proportional to $1-e_{i}$, they are increasing in $\beta_{i}$. This is often taken to mean that taxes on basic needs such as food should be high. Considering the possibility of home production (Sandmo 1990) suggests a somewhat different interpretation: Tax theory focuses on market demands rather than on consumption 
in the literal sense. If consumers can avoid taxes on specific market demands by home production, these demands should be taxed moderately. On the other hand, commodities like portables cannot be produced at home, and taxing them at high rates forces consumers to increase earnings. Following this interpretation, a high value of $\beta_{i}$ indicates that consumers cannot easily dispense with the respective market demand. Again, the relationship between consumption and earnings is crucial for the optimal tax rates.

\section{The Normalization Problem}

The above analysis uses the classical framework of a pure excise tax system. This specific normalization of the consumer price vector, which assumes the absence of a wage tax, is not as innocuous as it appears, nor does it present a serious obstacle for developing a meaningful theory of optimal commodity taxes. In what follows, all producer prices are set equal to unity, which can always be done by an appropriate choice of units. The above analysis involves a vector $\left(q_{0}, \boldsymbol{q}\right)$ of consumer prices. As consumption demands and effort are homogenous of degree zero in $\left(q_{0}, \boldsymbol{q}\right)$, the first component of this vector, the consumer price of leisure (or net wage rate), can also be chosen arbitrarily; and in the above analysis it was set to unity, implying that earnings remained untaxed. Thus, the variable $y$ represented both earnings and effort, and we obtained concrete optimal tax rates - which may be the relevant one in case of a less developed country that raises most tax revenue through excises.

To generalize, let us now write earnings more explicitly as $y=q_{0} \ell$, where $\ell$ represents effort. Introducing a wage tax means reducing $q_{0}$ somewhat. With total tax revenue given, this change does in no way influence the allocation. In the presence of a single commodity, for instance, it is immaterial whether we set $q_{1}=2$ and $q_{0}=1$ (a pure excise tax) or $q_{1}=1$ and $q_{0}=1 / 2$ (a pure wage tax). But the relative tax rates described by (11) are not invariant with respect to the normalization. This finding led Mirrlees (1976) to dismiss altogether the idea of characterizing optimal tax rates. However, this appears to push the point too far because, once we know the wage tax rate - and there is nothing to prevent us from doing so - we can infer the optimal commodity tax rates. These are uniquely defined, relative to the actual wage tax. The upshot is that calculating relative tax rates becomes possible once the wage tax is known. As the latter is public knowledge, an applied economist can easily use it. However, it is important to keep in mind - especially regarding Europe with its largely harmonized VAT regulations - that optimal commodity tax rates cannot be determined without regard to the actual mix of direct and indirect taxation ${ }^{7}$.

7 For a related study of the direct-indirect mix, see Smart (2002). 
For a theorist not interested in concrete numerical solutions, there is yet an easier way to cope with the normalization problem. All producer prices having been normalized to unity, the inequality $q_{\mathrm{i}}-q_{j}>0$ asserts unambiguously that commodity $i$ bears a higher tax than commodity $j$. The normalization of commodity prices affects only the size of the difference, not its sign. Substituting $t_{i}=q_{i}-1$ into (9), subtracting two such equations and rearranging yields

$$
q_{i}-q_{j}=-\frac{\lambda-\mu}{\mu}\left(e_{i}-e_{j}\right)
$$

It remains true that goods are taxed the more heavily, the smaller their index of encouragement. Indeed, the index of encouragement itself is invariant with respect to the normalization of the commodity price vector, and so is the difference $e_{i}-e_{j}$, which provides an abstract measure of relative tax burdens. Normalizations influence the difference of consumer prices solely through their effects on the Lagrangean multipliers. Since scaling up the price vector does not affect the sign of $q_{i}-q_{j}$, a theorist interested in qualitative properties can forget about normalization.

\section{CONCLUSION}

In this paper, an alternative route to characterizing second-best commodity taxes has been developed. It has been shown that optimal tax rates depend directly on the impact of consumption on earnings. If a higher consumption of a specific good like coffee induces the consumer to work harder, then this good should be taxed only moderately. Conversely, time-consuming activities should be taxed heavily. The intuition behind this result is straight-forward: As the government cannot tax leisure endowments directly, it should stimulate consumption of precisely the same goods which induce consumers to work harder. This move increases earnings as the genuine tax base and reduces the average tax rate, since total taxes paid remain constant. Work-related expenses should be taxed moderately or be made deductible under a wage tax.

In essence, the new tax rule can be considered as a generalization of the CorlettHague rule. It differs from the latter in three respects: Firstly, it holds for arbitrarily many commodities, and not just in the two-commodities case. Secondly, it characterizes optimal tax rates in terms of directly observable variables rather than in terms of unobservable compensated elasticities. And finally, the primal approach in the form invented here allows deriving expressions of optimal tax rates in a few lines, whereas the standard method follows a pretty roundabout course: It starts with characterizing optimal quantities using the dual approach, obtains the Ramsey rule, and finally re-translates the result into primal terms in order to describe the optimal tax rates. 
The last section has shown that optimal commodity tax rates can be determined without ambiguity once the wage tax is known. Since data on earnings, consumption, and prices are readily available, and since a researcher adopting this course does not need to know the utility function, it remains to be hoped that the approach proposed here will stimulate empirical research in the field.

\section{APPENDIX}

In order to render the mathematics air-tight, it is most convenient to make the following two assumptions: The utility function is strictly quasi-concave, and $\partial \boldsymbol{x} / \partial \boldsymbol{q}$ is negative definite ${ }^{8}$. Then, ordinary and inverse functions $\boldsymbol{x}(\boldsymbol{q})$ and $\boldsymbol{q}(\boldsymbol{x})$ exist. The excess demand function is the mapping $\left(q_{0}, \boldsymbol{q}\right) \rightarrow\left[\ell\left(q_{0}, \boldsymbol{q}\right), \boldsymbol{x}\left(q_{0}, \boldsymbol{q}\right)\right]$, whose Jacobian determinant vanishes, of course. $\partial \boldsymbol{x} / \partial \boldsymbol{q}$ is obtained from the Jacobian by deleting the first row and column. Note that we could also write effort in the more accustomed notation as $-x_{0}$ without affecting any of the above results. The present notation has been adopted because it is more intuitive.

Negative definiteness of $\partial \boldsymbol{x} / \partial \boldsymbol{q}$ - the famous "Law of Demand" which essentially rules out Giffen goods - is often assumed implicitly in optimal tax theory: Under the dual approach, post-multiplying equation (3) by the tax vector shows that precisely this assumption entails $\lambda>\mu$, since $\boldsymbol{t} \boldsymbol{x}>0$ and $\mu>0$. If the assumption were violated, $\lambda-\mu$ could become negative, implying that Ramsey taxes increase, rather than decrease, all uncompensated demands by a common factor. Therefore, the Law of Demand is the relevant assumption also in case of the dual approach. Under the primal approach, the relationship $\lambda>\mu$, which has been used in the interpretations, follows from pre-multiplying equation (7) by the consumption vector. Moreover, the analysis assumes existence of an optimum, excludes corner solutions and relies on an appropriate constraint qualification in order to have necessary optimality conditions.

The offer curve $y(\boldsymbol{x})$ is defined by the equation

$$
\frac{\partial u(\boldsymbol{x}, y)}{\partial \boldsymbol{x}} \boldsymbol{x}+\frac{\partial u(\boldsymbol{x}, y)}{\partial y} y=0
$$

which follows from combining equations (1), multiplying by $\boldsymbol{x}$ and using $\boldsymbol{y}=\boldsymbol{q} \boldsymbol{x}$. One can easily verify by non-vanishing Jacobian determinants that the offer curve exists if and only if the inverse demand functions exist, but owing to $y(\boldsymbol{x})=\boldsymbol{q}(\boldsymbol{x}) \boldsymbol{x}$, this is clear anyway. Maximizing consumers' utilities subject to $y-p \boldsymbol{x} \geq g$ and (23)

8 Some would speak of negative quasi-definiteness, because $\partial \boldsymbol{x} / \partial \boldsymbol{q}$ is not symmetric in general. Gale and Nikaido (1965), who proved global existence of inverse demand, would have called $-\partial \boldsymbol{x} / \partial \boldsymbol{q}$ a P-matrix. If one only wants local invertibility, the assumption of a regular equilibrium suffices. 
is an interesting way to state the optimal commodity tax problem, since taxes do not enter this formulation either directly or indirectly.

\section{REFERENCES}

Atkinson, A. B. und J. E. Stiglitz (1972) The Structure of Indirect Taxation and Economic Efficiency. Journal of Public Economics 1, S. 97-119.

Auerbach, A. J. and J. R. Hines (2002) Taxation and Economic Efficiency. In: Auerbach, A. J. and M. Feldstein (eds.) Handbook of Public Economics, Vol. III. Amsterdam: Elsevier.

Coady, D. and J. Drèze (2002) Commodity Taxation and Social Welfare: The Generalized Ramsey Rule. International Tax and Public Finance 9, pp. 265316.

Corlett, W. J. and D. C. Hague (1953) Complementarity and the Excess Burden of Taxation. Review of Economic Studies 21, pp. 21-30.

Deaton, A. S. (1979) The Distance Function and Consumer Behaviour with Applications to Index Numbers and Optimal Taxation. Review of Economic Studies 46, pp. 391-405.

Dupuit, A. (1844) De la mesure de l' utilité des travaux publics. Annales des ponts et chausseés. English in: Arrow, K. J. and T. Scitovsky (1969) Readings in Welfare Economics. Homewood: Irwin, pp. 255-283.

Gale, D. and H. Nikaido (1965) The Jacobian and Global Univalence of Mappings. Mathematische Annalen 159, pp. 81-59.

Mirrlees, J. A. (1976) Optimal Tax Theory - A Synthesis. Journal of Public Economics 6, pp. 327-358.

Myles, G. D. (1995) Public Economics. Cambridge: Cambridge University Press.

Ramsey, F. P. (1927) A Contribution to the Theory of Taxation. Economic Journal 37, pp. 47-61.

Samuelson, P. A. (1951) Theory of Optimal Taxation. Unpublished Memorandum for the U. S. Treasury. Published 1986 in: Journal of Public Economics 30, pp. 137-143.

Sandmo, A. (1987) A Reinterpretation of Elasticity Formulae in Optimum Tax Theory. Economica 54, pp. 89-96.

Sandmo, A. (1990) Tax Distortions and Household Production. Oxford Economic Papers 42, pp. 78-90.

Smart, M. (2002) Reforming the Direct-Indirect Mix. International Tax and Public Finance 9, pp. 143-155.

Stern, N. (1986) A Note on Commodity Taxation: The Choice of Variable and the Slutsky, Hessian and Antonelli Matrices (SHAM). Review of Economic Studies 53, pp. 293-299. 


\section{CESifo Working Paper Series}

(for full list see www.cesifo.de)

1168 Horst Raff and Nicolas Schmitt, Exclusive Dealing and Common Agency in International Markets, April 2004

1169 M. Hashem Pesaran and Allan Timmermann, Real Time Econometrics, April 2004

1170 Sean D. Barrett, Privatisation in Ireland, April 2004

1171 V. Anton Muscatelli, Patrizio Tirelli and Carmine Trecroci, Can Fiscal Policy Help Macroeconomic Stabilisation? Evidence from a New Keynesian Model with Liquidity Constraints, April 2004

1172 Bernd Huber and Marco Runkel, Tax Competition, Excludable Public Goods and User Charges, April 2004

1173 John McMillan and Pablo Zoido, How to Subvert Democracy: Montesinos in Peru, April 2004

1174 Theo Eicher and Jong Woo Kang, Trade, Foreign Direct Investment or Acquisition: Optimal Entry Modes for Multinationals, April 2004

1175 Chang Woon Nam and Doina Maria Radulescu, Types of Tax Concessions for Attracting Foreign Direct Investment in Free Economic Zones, April 2004

1176 M. Hashem Pesaran and Andreas Pick, Econometric Issues in the Analysis of Contagion, April 2004

1177 Steinar Holden and Fredrik Wulfsberg, Downward Nominal Wage Rigidity in Europe, April 2004

1178 Stefan Lachenmaier and Ludger Woessmann, Does Innovation Cause Exports? Evidence from Exogenous Innovation Impulses and Obstacles, April 2004

1179 Thiess Buettner and Johannes Rincke, Labor Market Effects of Economic Integration The Impact of Re-Unification in German Border Regions, April 2004

1180 Marko Koethenbuerger, Leviathans, Federal Transfers, and the Cartelization Hypothesis, April 2004

1181 Michael Hoel, Tor Iversen, Tore Nilssen, and Jon Vislie, Genetic Testing and Repulsion from Chance, April 2004

1182 Paul De Grauwe and Gunther Schnabl, Exchange Rate Regimes and Macroeconomic Stability in Central and Eastern Europe, April 2004 
1183 Arjan M. Lejour and Ruud A. de Mooij, Turkish Delight - Does Turkey's accession to the EU bring economic benefits?, May 2004

1184 Anzelika Zaiceva, Implications of EU Accession for International Migration: An Assessment of Potential Migration Pressure, May 2004

1185 Udo Kreickemeier, Fair Wages and Human Capital Accumulation in a Global Economy, May 2004

1186 Jean-Pierre Ponssard, Rent Dissipation in Repeated Entry Games: Some New Results, May 2004

1187 Pablo Arocena, Privatisation Policy in Spain: Stuck Between Liberalisation and the Protection of Nationals' Interests, May 2004

1188 Günter Knieps, Privatisation of Network Industries in Germany: A Disaggregated Approach, May 2004

1189 Robert J. Gary-Bobo and Alain Trannoy, Efficient Tuition Fees, Examinations, and Subsidies, May 2004

1190 Saku Aura and Gregory D. Hess, What's in a Name?, May 2004

1191 Sjur Didrik Flåm and Yuri Ermoliev, Investment Uncertainty, and Production Games, May 2004

1192 Yin-Wong Cheung and Jude Yuen, The Suitability of a Greater China Currency Union, May 2004

1193 Inés Macho-Stadler and David Pérez-Castrillo, Optimal Enforcement Policy and Firms' Emissions and Compliance with Environmental Taxes, May 2004

1194 Paul De Grauwe and Marianna Grimaldi, Bubbles and Crashes in a Behavioural Finance Model, May 2004

1195 Michel Berne and Gérard Pogorel, Privatization Experiences in France, May 2004

1196 Andrea Galeotti and José Luis Moraga-González, A Model of Strategic Targeted Advertising, May 2004

1197 Hans Gersbach and Hans Haller, When Inefficiency Begets Efficiency, May 2004

1198 Saku Aura, Estate and Capital Gains Taxation: Efficiency and Political Economy Consideration, May 2004

1199 Sandra Waller and Jakob de Haan, Credibility and Transparency of Central Banks: New Results Based on Ifo's World Economicy Survey, May 2004

1200 Henk C. Kranendonk, Jan Bonenkamp, and Johan P. Verbruggen, A Leading Indicator for the Dutch Economy - Methodological and Empirical Revision of the CPB System, May 2004 
1201 Michael Ehrmann, Firm Size and Monetary Policy Transmission - Evidence from German Business Survey Data, May 2004

1202 Thomas A. Knetsch, Evaluating the German Inventory Cycle - Using Data from the Ifo Business Survey, May 2004

1203 Stefan Mittnik and Peter Zadrozny, Forecasting Quarterly German GDP at Monthly Intervals Using Monthly IFO Business Conditions Data, May 2004

1204 Elmer Sterken, The Role of the IFO Business Climate Indicator and Asset Prices in German Monetary Policy, May 2004

1205 Jan Jacobs and Jan-Egbert Sturm, Do Ifo Indicators Help Explain Revisions in German Industrial Production?, May 2004

1206 Ulrich Woitek, Real Wages and Business Cycle Asymmetries, May 2004

1207 Burkhard Heer and Alfred Maußner, Computation of Business Cycle Models: A Comparison of Numerical Methods, June 2004

1208 Costas Hadjiyiannis, Panos Hatzipanayotou, and Michael S. Michael, Pollution and Capital Tax Competition within a Regional Block, June 2004

1209 Stephan Klasen and Thorsten Nestmann, Population, Population Density, and Technological Change, June 2004

1210 Wolfgang Ochel, Welfare Time Limits in the United States - Experiences with a New Welfare-to-Work Approach, June 2004

1211 Luis H. R. Alvarez and Erkki Koskela, Taxation and Rotation Age under Stochastic Forest Stand Value, June 2004

1212 Bernard M. S. van Praag, The Connexion Between Old and New Approaches to Financial Satisfaction, June 2004

1213 Hendrik Hakenes and Martin Peitz, Selling Reputation When Going out of Business, June 2004

1214 Heikki Oksanen, Public Pensions in the National Accounts and Public Finance Targets, June 2004

1215 Ernst Fehr, Alexander Klein, and Klaus M. Schmidt, Contracts, Fairness, and Incentives, June 2004

1216 Amihai Glazer, Vesa Kanniainen, and Panu Poutvaara, Initial Luck, Status-Seeking and Snowballs Lead to Corporate Success and Failure, June 2004

1217 Bum J. Kim and Harris Schlesinger, Adverse Selection in an Insurance Market with Government-Guaranteed Subsistence Levels, June 2004 
1218 Armin Falk, Charitable Giving as a Gift Exchange - Evidence from a Field Experiment, June 2004

1219 Rainer Niemann, Asymmetric Taxation and Cross-Border Investment Decisions, June 2004

1220 Christian Holzner, Volker Meier, and Martin Werding, Time Limits on Welfare Use under Involuntary Unemployment, June 2004

1221 Michiel Evers, Ruud A. de Mooij, and Herman R. J. Vollebergh, Tax Competition under Minimum Rates: The Case of European Diesel Excises, June 2004

1222 S. Brock Blomberg and Gregory D. Hess, How Much Does Violence Tax Trade?, June 2004

1223 Josse Delfgaauw and Robert Dur, Incentives and Workers' Motivation in the Public Sector, June 2004

1224 Paul De Grauwe and Cláudia Costa Storti, The Effects of Monetary Policy: A MetaAnalysis, June 2004

1225 Volker Grossmann, How to Promote R\&D-based Growth? Public Education Expenditure on Scientists and Engineers versus R\&D Subsidies, June 2004

1226 Bart Cockx and Jean Ries, The Exhaustion of Unemployment Benefits in Belgium. Does it Enhance the Probability of Employment?, June 2004

1227 Bertil Holmlund, Sickness Absence and Search Unemployment, June 2004

1228 Klaas J. Beniers and Robert Dur, Politicians' Motivation, Political Culture, and Electoral Competition, June 2004

1229 M. Hashem Pesaran, General Diagnostic Tests for Cross Section Dependence in Panels, July 2004

1230 Wladimir Raymond, Pierre Mohnen, Franz Palm, and Sybrand Schim van der Loeff, An Empirically-Based Taxonomy of Dutch Manufacturing: Innovation Policy Implications, July 2004

1231 Stefan Homburg, A New Approach to Optimal Commodity Taxation, July 2004 